\title{
Research on Improving Validity of Public Participation on Rail Transits
}

\author{
Cheng Song ${ }^{1}$, Huan Wang and Jiahong Zhao \\ Groundwater of Rrought Region and Ecological Effect Laboratory, Chang'an University Xi'an 710064, China
}

\begin{abstract}
The rail transit is playing an important role in solving ground traffic congestion, guiding urban space layout and improving effectiveness of land using. The public are paying more and more attention to its social influences and environmental problems in construction and operation stages. This paper analyses traits of rail transit's environmental impact and sums up the influencing factors in public participation by considering construction contents and environmental impact of the first project stage of Xi'an subway 5 th line. Finally it draws the conclusion that whole-process public participation, diverse ways of information disclosure, more representative survey samples, more accurate and efficiency data statistic and valid public feedback can be the main ways for improving validity of public participation, lowing rail transit's environmental and social impact and enhancing the sustainable development of rail transit.
\end{abstract}

Keywords-public participation; validity; rail transit; environmental impact assessment; whole-process

\section{INTRODUCTION}

The rail transit has great advantages in solving urban traffic congestion,improving efficiency of urban transportation space and optimizing urban layout with the qualities such as large traffic capacity, high speed, punctuality and comfort. At the end of April 2014, China has built more than 60 rail transits in 25 cities, whose length has reached $2900 \mathrm{~km}$.

The rail transit belongs to super large urban infrastructure because of its large-scale and long construction period. It is mainly located in urban areas where density of population, existing building and public facilities is high. In addition, the public pays high attention to environmental problems during the construction and operation stages of the project. Public participation is the important platform that ensures information exchange among decision departments, construction units and the public, and also it is one of the measurements that enhance project's scientific decision-making, social acceptability and pertinence and validity of environment protection. We have made breakthroughs in the work procedure of environmental impact assessment after 10 years' development. But in terms of the results of practice of public participation, there're still some existing problems such as the validity-lacking of samples, singleness of information disclosure, pertinence lacking of design of questionnaire and statistical analysis.Thus the effectiveness of public participation becomes the core problem in environmental impact assessment of rail transits. Domestic and foreign experts in environment management think that the main factors affecting validity of public participation are participants $^{[1-2]}$,ways of information disclosure ${ }^{[3]}$, participation time $\mathrm{e}^{[4]}$ and design of questionnaire ${ }^{[5]}$.In addition, perfecting laws and regulations, improving supervision mechanism and media intervention are fundamental guarantees for improving Validity. Based on the first project stage of Xi'an Subway 5th Line, this paper deeply dissects factors that help improving validity of public participation in environmental impact assessment and finally puts forward specific advice.

\section{TRAITS OF ENVIRONMENTAL IMPACTS CAUSED BY RAIL TRANSIT}

\section{A. Long Construction Stage and Significant Environmental Impacts During Construction}

Rial transit's construction stage usually lasts for 4-5years,earthwork volume is large in the construction process of metro station and section. Earthwork construction and transportation can cause noise, vibration, solid waste, waste water and fugitive dust problems, which also adds uncertainties to the normal use of existing pipelines along. The water-lowing process during earthwork construction has some influence on groundwater level and stability of surrounding foundation. In addition, the massive building materials and machinery will occupy traffic artery leading to traffic conges-tion,which hinders the normal traffic. The public have strong opposition to the environmental problems in construction stage.

\section{B. The Environmental Impact is Clear and Environmental Problems are Concentrated}

The main source of environmental problems in construction stage are noise, vibration, solid waste, waste water and fugitive dust caused by earthwork construction.The main source of environmental problems in operation stage are vibration, noise and electromagnetic radiation caused by normal operation of rail transit. The public have certain cognition about environmental problems in different stages. The unreasonable environment measurement will lead to public opposition, even environmental group conflicts.

\section{The Impact is Controllable, but the Remedy Measurements are Difficult to Implement}

Rail transit has a set of technically mature skills preventing environment problems. Usually the elevated line and ground line can set noise barrier, ventilation pavilion and cooling tower can set muffler to satisfy sound requirements of different areas. The underground line can take damping measurement to limit vibration within allowable vibration standard. The main substations can satisfy environmental standards by changing construction sites and methods. The difficulties of environmental remediation measures' implementing are pretty high, especially the replacement of damping facilities in 
operation stage can be even hard.(e.g. The steel spring floating slab track bed).The cost can also be high.

\section{Environment Sensitive Points are Dense, and Social Attention is High}

To ease the traffic pressure on the ground, rail transits are laid in areas with large passenger volume. There are many points deserving attention: highly dense sensitive points along, complicated condition of pipelines, ground and underground cultural relics in some areas and huge environmental impact contents. In addition, to meet the design requirement of minimum curve radius of railway plane line, some rail transit lines have to run below the sensitive buildings[6].The negligence and incomplete implementing of environmental measurements are likely to cause environmental dispute,increasing the risk of social instability.

\section{Engineering Situation OF the First Project Stage OF XI'AN SUBWAY 5TH LINE}

The project starts from the heping station in the west, and goes east through the Kunming road, Youyi road, Yanxiang road and other planned stations, ending at the Changming station at the Chang ming crossroad. The first project stage of Xi'an Subway 5th Line is a component project in "Xi'an urban rapid rail transit construction planning (2013-2018)”.The main part of the line is underground, whose length reaches $24.05 \mathrm{~km}$. The Chanhe section is elevated, whose length is $0.97 \mathrm{~km}$. The transition section of bridge and tunnel is $0.24 \mathrm{~km}$. There are 18 stations,2 parking stations located at the Epang Palace and the Yanming Lake. There are also 2 main substations. The first project stage of Xi'an Subway5th Line started construction in 2014,planning to finish in 2018.According to survey result, there're 100 vibration controlling points, most of which are residential buildings, schools, office buildings of research institutions. The rail traverses directly below 12 of the 100 sensitive points. Ventilation pavilions and cooling towers have 23 noise reduction and air protection targets, most of which are residential buildings and office buildings. The Rongjiazhai substation has a residential point around itself. In addition, Chang'an city sites of Sui and Tang dynasties, the Lesser Wild Goose Pagoda and the Qinglong Temple are the 3 cultural relics protection points.

\section{The IMPLEMENTING OF THE PUBlic PARTICIPATION IN FIRST PROJECT STAGE OF XI'AN SUBWAY 5TH LiNE}

There are diverse sensitive points along the first phrase project of Xi'an Subway 5th Line. They differ in traits and influence degrees caused by the project. Therefore, public participation's procedure, form, content and requirement should not only satisfy commonness of construction projects, but also highlight the traits of rail transits[7].In the process of public participation, we enforce validity from the following aspects.

\section{A. Whole-process Participation}

The earlier the public participate in environmental impact assessment, the more acceptable policy adjustment would be, the less the cost would be, which helps improving validity of public participation.

In order to craft decision of the project, environment assessment group visited $\mathrm{Xi}$ ' an Bureau of cultural relics, the Planning Bureau and other relevant government departments as well as the experts in environment protection, planning, city management, groundwater and cultural relic protection at the early planning stage of Xi'an rail transit. Then we step in environmental impact assessment stage after ensuring that there's no environmental limitation factors to the project. At the early stage of environ-mental impact assessment, environment assessment group collected the opinion of the participants as fundamental materials of environmental assessment work. Environmental assessment group did public survey aiming at the environment sensitive points after the environmental impact assessment report was preliminarily finished. This project reinforces the public's participation right and the right to know the environment, and gives full consideration to public's environmental rights and interests under adverse effect by adopting public participation in environmental impact assessment in whole process. In addition, it improves the effectiveness of public participation and the acceptability of public.

\section{B. Recognizing the Stakeholder and Choosing the Representative Samples}

Correct recognition of stakeholders is the foundation for improving validity of public participation. We comply with two principles when choosing participants: first, choose different stakeholders in different stages; second, comprehensively consider characteristics of environmental impact and the degree that environment was affected by the project. We did 2 times public surveys and sent out 400 pieces of questionnaires.14 people refused survey(the proportion is 3.5\%).We collected 386 questionnaires, and 376 of them are valid. In the 198 questionnaires of the first survey,160 (the proportion is $80.8 \%$ ) come from the people who work and live within $60 \mathrm{~m}$ from the line. And the other 38(the proportion is 19.2)come from people who care about the project; In the second survey,178 pieces of questionnaires all come from the ones. negatively affected by project.138 come from people affected by vibration(we collected 45 pieces of questionnaires at 12 points below which the train pass). There are 40 questionnaire-s within $30 \mathrm{~m}$ from ventilation pavilionsand cooling towers. The two surveys has inquire 338 people affected by the project, making up $90 \%$ of the samples. The public participation focused more on people affected and the protective measurements, which can get wider support from the public.

\section{Adopted Diverse Means of Public Disclosure}

We publicize information through influential news-papers and official web of rail transit. Taking into account the public who lives along the project need more detailed EIA information. We also posted public announcement in the environment sensitive along the project. We also send out "A letter to the public" to the public, introducing project's impact categories, degree, measurement that will be taken and effects to people who live or work along.

\section{Enhance the Pertinence of Investigation through Diverse Ways of Public Participation}

Combined with the traits of the project's environmental impact and the sensitivity of the environmental problems along the rail transit. We use the following forms: Firstly, we 
interview stakeholders through questionnaires and talking. Secondly, we interview experts through half open type of expert counseling. Thirdly, the survey of related organizations and the government of the area along the project use open questionnaire survey. Fourthly, we held public forum on the issues of hot environmental sensitive problems. Take different participation styles according to different types of participants, which not only improve the efficiency of the public participation, but also obtain the comments and suggestions that numerous improve the EIA and environmental protection measures of project.

\section{E. Reasonably Design the Questionnaire by Detailed and Targeted Content}

Questionnaire is one of the most common methods for public participation. Scientifical design of the questionnaire is the important the basis of the investigation and statistical analysis. The survey questionnaire must ensure the authenticity and effectiveness of the public information, the comprehensive and targeted of survey content, the organization and gradation of structure arrangement, the conciseness and understandability of problem description. The questionnaire of this project adopts the form of combination of closing and opening problems. Personal surveys along the rail transit are conducted through closed questions, while the question- naires of experts, enterprises, social organizations and relevant government agencies are through open questions.

\section{F. Choose a Effective Statistical Method of Public Opinion}

Statistic is the premise to deal with public opinion, screening effective suggestions and ignoring invalid opinion. We use both qualitative and quantitative methods. And we choose SPSS software for statistic. Statistical analysis is focused on:(1)Valid questionnaire ratio and rejective ratio.(2)Public attitudes towards project.(3)Analysis of opinion from people who are at sensitive points.(4)Analysis of the hot environmental protection targets and environmental impact during project construction and operation period.(5)Public advice on protection measures.(6)Summarizing all kinds of public response to the open questions. Analyzing opinions of experts and relevant units and organizations with qualitative methods. Focusing on the analysis of environmental problems, limitation and available measurements.

\section{G. Pay Attention to the Information Feedback Processing of Public Opinion}

The implementation and disposal of public opinion are the ultimate focus of the public participation's effectiveness, which can effectively avoid the occurrence of environmental disputes in the later period. Therefore, the project feeds back the opinions of the implementation and handling of public participation to the relevant public by telephone or written notice. Electromagnetic radiation is a hot focus in public attention. The emissions of both electric field and magnetic field of the two main substation of this project are much lower than the national recommended standard. The public also worried about this. So we turned the Rongjiazhai substation to beunderground to dispel concerns, adding ten million budget.

\section{CONCLUSION}

From the analysis above, we has given the following conclusions:(1)establish management mechanism about public participation's influencing factor;(2)Improve trans-parency via environmental information, participation process, opinion feedback and decision action;(3)Put whole-process participation into action;(4)Pay more attention to people who are within $10 \mathrm{~m}$ from central line, 50 from substation, $30 \mathrm{~m}$ from ventilation pavilion and people influenced by project removing;(5)Pay attention to open questions and feed the result back to public.

\section{ACKNOWLEDGMENT}

The authors would like to thank the central university basic scientific research expenses funded project(310829161007) and the province social science fund project of Shaanxi(2015G016), Key Laboratory of subsurface Hydrology and Ecological Effects in Arid Region, Ministry of Education.

\section{REFERENCE}

[1] The World Bank. Public Involvement in Environmental Assessment: Requirements, Opportunities and Issues[R]. Washington D.C, the World Bank.1993.

[2] Liu Lei, Li Jiwen, Wu Chunxu. Reach on Improving Effectiveness of Public Participation in EIA [J].Sichuan Environment,2009,28(1):85-89.

[3] Chen Xin. Research on the Effectiveness of Public Participation in Environmental Impact Assessment Based on the Effective Management Model[D].Jilin Jilin University,2010,6.

[4] Mein hard Doelle, A. John Sinclair. Time for a new approach to public participation in EA [J]: Promoting cooperation and consensus for sustainability. Environmental Impact Assessment Review 2006, 26:185-205.

[5] Susan Charnley, Bruce Engel bert. Evaluating public participation in environmental decision-making[J]: EPA's superfund community involvement program. Journal of Environmental Management 2005,77:165-182.

[6] Liu Yang, Xing Xiaoan. Issues that deserve attention in the Environmental Impact Assessment of Urban Rapid Rail Transit [J].Urban Rapid Rail Transit,2005,18(5):98-100.

[7] Zhang Lei. The key points of environmental impact assessment of Rail Transit Project[J].Environmental Protection,2011(15):50-53. 